Revista de

Contabilidade e

Organizações

www.rco.usp.br
DOI: http://dx.doi.org/10.11606/issn.1982-6486.rco.2018.143924
Journal of

Accounting and

Organizations

\title{
Reflexões sobre o estabelecimento de preços a partir dos custos e dos preços das ofertas concorrentes: a lacuna pode não ser tão profunda
}

Reflections on cost-based pricing and competition-based pricing: the gap may not be so deep

Juliana Ventura Amaral ${ }^{\mathrm{a}}$; Reinaldo Guerreiro ${ }^{\mathrm{a}}$

${ }^{a}$ Universidade de São Paulo

Palavras-chave

Formação de preços.

Custos.

Concorrência.

Valor.

Custos mais margem.
Keywords

Pricing.

Costs.

Competition.

Value.

Cost plus pricing.

\section{Resumo}

As pesquisas sobre estabelecimento de preços apontam uma lacuna, de um lado os preços de produtos e serviços deveriam ser definidos pautados no valor entregue ao cliente, por outro os preços são de fato definidos com base nos custos incorridos ou nos preços das ofertas concorrentes. Diante disto, o artigo aponta as circunstâncias em que as empresas, durante o estabelecimento dos preços (pelos custos ou pelas ofertas concorrentes), consideram ou não o valor de seus produtos ou serviços. Para isso, foi feito um levantamento em empresas industriais brasileiras, com a obtenção de 380 respostas junto a profissionais responsáveis pela fixação de preços. Os resultados indicam que as empresas definem seus preços a partir daqueles estipulados pelos concorrentes e a partir dos custos, mas não, necessariamente, desprezam a informação do valor de seu produto.

\begin{abstract}
Studies on price setting indicate a gap, prices of products and services should be set based on their value to customers (value-based prices), but actually are set based on costs and on products by competitors (cost-based prices and competition-based prices). Thus, the study identifies the circumstances where cost-based prices and competition-based prices have not mean necessarily prices not based on the value of the firms' product and services. We run a survey to Brazilian industrial firms, and the answers by 380 pricing professionals suggest that the firms setting cost-based prices and competition-based prices do not necessarily ignore the value of the associated product.
\end{abstract}

\section{Implicações práticas}

Controllers, consultores de marketing, gestores de vendas e demais profissionais devem atentar que as fórmulas de fixação de preço do tipo "custo mais margem" têm sido empregadas de forma combinada com informações de valor dos produtos e de preços das ofertas da concorrência, dependendo da postura de formadoras ou tomadoras de preços. Considerando preços de referência de mercado, mas também outras bases para fixação do preço de produtos e serviços.

Copyright $(2018$ FEA-RP/USP. Todos os direitos reservados

\section{INTRODUÇÃO}

$\mathrm{Na}$ literatura sobre formação de preços, especialmente na oriunda do marketing, recomenda-se que os preços sejam definidos com base no valor que o produto oferece ao cliente. Piercy, Cravens e Lane (2010), por exemplo, defendem que quando os preços não são estabelecidos com base no valor do produto ou serviço, as empresas entram em um ciclo vicioso, que só prejudica seu desenvolvimento. Afinal, como elas são obrigadas a competir em função de preço não veem quaisquer motivos para oferecer soluções de valor, preferindo oferecer pouco valor, por um menor preço.

Autor Correspondente: Tel. (11) 3091-5820

E-mail: juliana.ventura.amaral@usp.br (J. V. Amaral); reiguerr@usp.br (R. Guerreiro)

Universidade de São Paulo. Avenida Professor Luciano Gualberto, 908 - CEP 05508-900 - São Paulo - SP - Brasil. 
$\mathrm{Na}$ prática, os estudos sobre o estabelecimento de preços sugerem que os preços na realidade são definidos com base nos custos ou nas ofertas da concorrência, e não no valor do produto ou serviço oferecido ao cliente. Ingenbleek (2007), após revisar 53 pesquisas empíricas, concluiu que a maior parte das empresas determina os preços a partir de informações de custos. Enquanto, os estudos empíricos revisados por Hinterhuber (2008) apontam que os preços são definidos a partir do preço das ofertas dos concorrentes ou dos custos. Mais recentemente, Calabrese e Francesco (2014) também concluíram que as empresas definem seus preços com base em ofertas da concorrência e em seus próprios custos.

Do contraste entre a sugestão de uso do valor entregue ao cliente e da prática do preço baseado em custos e concorrência, argumenta-se que há uma lacuna entre como os preços devem ser definidos e como de fato são definidos (Ingenbleek, 2007; Hinterhuber, 2008; Calabrese \& Francesco, 2014). Contudo, argumentamos que estabelecer preços baseados nos custos e nas ofertas concorrentes não implica, necessariamente, em desconsiderar o valor entregue aos clientes da fixação do preço. Tal questão ainda aflige os profissionais que atuam na fixação de preços, pois o uso de informações desconectadas do valor do produto ou serviço pode estar associado à falência de muitas empresas (Hinterhuber, 2016).

Destacamos que empresas formadoras e tomadoras de preços devem ser tratadas de forma distinta. As empresas caracterizadas como tomadoras de preços, como as oferecedoras de commodities e de produtos padronizados, sobretudo no mercado de consumo (business-to-consumer - B2C), monitoram e se inspiram nos preços das ofertas concorrentes para definir seus próprios preços (Strickland, 2007; Simons, 2012), mas, necessariamente, não ignoram a noção do valor do produto nas suas decisões. Já as formadoras de preços utilizam fórmulas de custeio (Drury \& Tayles, 2006), mas nada as impede de usar de forma combinada o valor entregue aos clientes ao adicionar a margem de contribuição aos custos dos produtos e serviços nas fórmulas adotadas.

\section{ESTRUTURA CONCEITUAL E HIPÓTESES}

Os trabalhos empíricos e as revisões da literatura indicam que os preços não são definidos com base no valor do bem ou serviço entregue aos clientes. A principal causa seria o domínio dos custos do produto ou dos preços das ofertas concorrentes para a formação de preços (Ingenbleek, 2007; Hinterhuber, 2008; Calabrese \& Francesco, 2014). O problema é que essa conclusão é inferida sem considerar, pelo menos, quatro especificidades do processo de estabelecimento dos preços.

\section{Nem todas as empresas têm poder para formar preços}

Embora presente entre os economistas, a segregação das empresas entre as que "formam preços" (formadoras) e as que "tomam preços" (tomadoras) normalmente é ignorada em outras áreas do conhecimento (Tishlias, 1984; Chand, 2009) (e.g., marketing, contabilidade).

Parc incorporar a mencionada distinção no debate de fixação de preços, a análise deve considerar a capacidade das empresas em gerar diferenciações nos produtos e serviços ofertados (Banterle, Carraresi \& Cavaliere, 2(11). Quando a empresa oferece produtos similares às ofertas concorrentes, ela tem menos poder sobre a definição de seus preços, pois dada a semelhança das ofertas, os consumidores priorizam o preço e não se importam com qual empresa produz o produto ou serviço. Nessa situação, a empresa não teria escolha e precisaria tomar o preçı determinado pelo mercado como um todo (Hofstrand, 2007).

Já quando a empresa oferece produtos diferentes dos concorrentes, ela tem mais autonomia para definir seus preços, de acordo com a importância que os clientes dão aos diferenciais da oferta. Nessa situação, ela disporia, em alguma extensão, de poder para formar preços. O grau de diferenciação percebida pelos compradores e a importância por eles atribuída a essa diferenciação afetaria o poder da empresa sobre o estabelecimento dos preços (Oxenfeldt, 1961).

H1: A diferenciação do produto é positivamente associada ao poder de formar preços. Quanto menos diferenciados os produtos, maior é a necessidade de tomada de preços e menor é a possibilidade de nortear o processo de acordo com o valor. 
Sabe-se que uma empresa pode não ser totalmente formadora de preços, ou tomadora de preços, mas predominantemente formadora ou tomadora, dependendo do portfólio de produtos e serviços que oferta (predominância de um portfólio de produtos e serviços com maior ou menor diferenciação em relação aos concorrentes). Certos setores, como o de commodities (i.e., milho, siderurgia) e de produtos padronizados no B2C (i.e., macarrão instantâneo), naturalmente têm uma maior tendência a apresentarem empresas tomadoras de preços, enquanto outros, como bens de luxo no B2C e máquinas customizadas no mercado industrial (business-to-business - B2B), têm maior propensão a serem formadoras de preços.

\section{Tomadoras e formadoras: preços a partir de diferentes informações}

Os preços praticados pelas empresas tomadoras de preços são inspirados nos preços das ofertas disponíveis no mercado. Diferente do que ocorre nas empresas formadoras de preços, cujos produtos sem substitutos diretos não precisam refletir na mesma intensidade os preços de ofertas no mercado.

Nas tomadoras de preços, conforme já mencionado, o alinhamento ao preço do mercado é a opção mais sensata (Simons, 2012). No entanto, tomar o preço de mercado não implica o uso exclusivo de informações das ofertas da concorrência. Afinal, as tomadoras têm acesso a dados externos (i.e., disponibilidade dos preços de produtos similares oferecidos pelos concorrentes; valor percebido por demanda de clientes), e também a dados internos (i.e., os custos do produto e a estrutura de custos dos processos da própria empresa). A ausência de poder de fixar o preço não configura uma justificativa para desconsiderar que a operação interna é a responsável pela eficiência de produção, afetando a viabilidade de certo preço praticado pelo mercado (Strickland, 2007).

Para empresas formadoras de preços, dada a menor similaridade das ofertas concorrentes, é ao mesmo tempo mais difícil balizar preços pelo mercado e maior o poder para não se alinhar ao mercado. Por exemplo, a dificuldade pode vir da falta de listas de preços distribuídas para ofertas concorrentes (Dutta, Zbaracki \& Bergen, 2003). Assim, a fixação de preços parte de referências internas, como custos de produção e logística. O fato de usar os custos como base para preços não significa, contudo, que análises sobre o valor dos produtos e serviços entregue aos clientes não podem ser incorporadas.

H2a: Empresas tomadoras de preços usam informações dos preços das ofertas concorrentes, dos custos e de valor ao cliente para estabelecerem os preços.

H2b: Empresas formadoras de preços usam informações dos custos e de valor ao cliente para estabelecerem os preços.

\section{Tomadoras e formadoras: uso de fórmulas para cálculo do preço}

Já em 1952, Edwards (1952) indicava que as empresas costumam empregar fórmulas matemáticas para determinar seus preços. Afinal, o uso de fórmulas permite não só calcular os preços, mas também justificar os preços que inevitavelmente devem ser praticados. Assim, enquanto as empresas tomadoras de preços usam fórmulas para ajustar os preços tomados do mercado, as empresas formadoras de preços usam fórmulas para fixar preços (aceitos pelos clientes) visando a sustentabilidade do lucro.

Algumas fórmulas são bastante simples e outras são sofisticadas (Avlonitis \& Indounas, 2006). As fórmulas que partem dos preços dos concorrentes, comuns nas tomadoras de preços, são, por exemplo: "preço de venda = preço dos concorrentes no mercado" e "preço de venda = preço dos concorrentes no mercado $+/$ - ajustes" (Avlonitis \& Indounas, 2005). Mas nas tomadoras de preços também é comum encontrar fórmulas que partem dos custos, as quais são frequentemente empregadas pelas formadoras de preços (Drury \& Tayles, 2006).

Logo, a fórmula "custos mais margem" pode estar presente tanto nas formadoras quanto nas tomadoras de preços. Assim, não é difícil entender por que Wentz (1966) já havia reconhecido a ampla utilização da fórmula pelas empresas e por que a maioria das pesquisas empíricas ratifica esse reconhecimento.

H3: Fórmulas do tipo “custos mais margem” são encontradas tanto nas tomadoras quanto nas formadoras de preços. 


\section{A essência do processo não é indicada pela fórmula usada}

Argumentamos que não é por que as empresas usam a fórmula "custos mais margem", sejam tomadoras ou formadoras de preços, que os preços são fixados unicamente com base nos custos. Afinal, nas tomadoras de preços a combinação "custos mais margem" pode ser empregada para balizar o processo de fixação, ainda que os preços finais devam equiparar-se aos preços do mercado (Lere, 1979; Drury \& Tayles, 2006). Para tanto, há duas opções: ou a margem já espelha os preços dos concorrentes (eventualmente ajustados por diferenças no valor da proposta entregue), o que possibilita a determinação dos preços em uma única etapa, ou a margem inicialmente proposta é arbitrária, com ajuste posterior no preço para equiparar-se aos preços das ofertas concorrentes.

Nas empresas formadoras de preços, o emprego da combinação “custos mais margem”, além de viabilizar que a fixação de preços assegure a cobertura dos custos e a geração do lucro desejado, pode fazer com que o valor do produto ou serviço entregue seja considerado por intermédio da margem (Indounas, 2006). Como números fechados não são capazes de incorporar as condições de mercado nem o peso de um determinado cliente ou mesmo a importância de um determinado produto (Haynes \& Wilkens, 1974), poderia ser esperado que as empresas reconhecessem esse risco de certa forma. Assim, talvez seja um grande equívoco afirmar que quando a fórmula “custos mais margem” é usada, apenas os custos são considerados pelas empresas (Foxall, 1972; 1980).

Portanto, o uso da fórmula "custos mais margem" não significa que os custos são a essência do processo, em alguns casos pode ser simplesmente a mecânica de operacionalizar o estabelecimento dos preços.

H4: O uso da fórmula "custos mais margem" não é, necessariamente, sinônimo de um estabelecimento de preços que tem os custos como essência. Quando a margem conecta informações de custos a informações de preços das ofertas concorrentes (tomadoras de preço) e de valor de produtos e serviços (formadoras de preços), tem-se a forma de fixação do preço, mas não a essência baseada nos custos.

\section{DADOS E MÉTODO}

Os dados foram coletados mediante um levantamento (survey) disponibilizado em uma página na internet e como um anexo de mensagens eletrônicas enviadas aos profissionais que atuam na fixação de preços. Realizamos um pré-teste dividido em três etapas para assegurar a validade do questionário, sendo a primeira fase direcionada a três pesquisadores, a segunda a dois consultores e a terceira a dezesseis potenciais respondentes.

Optamos por restringir o foco do levantamento a empresas industriais, usando a lista de empresas disponibilizada pela revista Exame Melhores e Maiores e pela revista NEI (Noticiários de Equipamentos Industriais). A partir dessa lista, as 1.616 empresas identificadas foram consideradas como população da pesquisa. O questionário foi enviado para 1.544 empresas. Optamos por não enviar àquelas empresas da população cujo setor não era de fato industrial bem como àquelas envolvidas em processo de recuperação judicial e na operação Lava Jato.

Com a obtenção de 395 respostas ao questionário e com uma amostra final de 380 empresas (taxa de resposta de 26\%), a amostra caracteriza-se como não probabilística. Eliminamos 15 respostas, por estarem incompletas (8 casos), ou de preenchimento incorreto (2 casos), entregues a outro profissional não especializado da empresa (3 casos), ou oriundas de empresas não componentes da população da pesquisa (2 casos).

Para assegurar a validade simultânea, foi analisado o viés da não resposta, nos moldes de Armstrong e Overton (1977), em que os participantes que prontamente respondem o questionário assemelham-se aos respondentes e os participantes que respondem após reiterações equiparam-se aos não respondentes. Não foram observadas diferenças estatisticamente significativas entre os dois grupos. Já para avaliar a confiabilidade da pesquisa, foi calculado o alfa de Cronbach. O resultado de 0,794 indicou que a pesquisa poderia ser considerada confiável (Maroco \& Garcia-Marques, 2006).

O questionário utilizado, que está disponível no Apêndice A, inclui cinco construtos captados por questões abertas, de múltipla escolha ou que empregam a escala Likert de cinco pontos. O primeiro construto aborda a classificação da empresas em tomadoras ou formadoras de preços. Inferimos o enquadramento a partir de três variáveis definidas para investigar se há ou não decisão a ser tomada com relação aos preços. A primeira variável alinha-se às constatações de Harper (1966), Hofstrand (2007) e D’Aveni (2009) de que as empresas de commodities ofertam produtos idênticos aos concorrentes e precisam necessariamente tomar os preços disponíveis no mercado. A segunda variável investiga a diferenciação, que os clientes percebem, para os produtos ofertados no mercado de consumo (B2C). Essa variável foi definida a partir da arguição de Maxwell (1998) de que as decisões de preços no mercado de consumo normalmente são guiadas coletivamente pela competição, tendo em vista a similaridade dos produtos. 
Empresas do mercado de consumo oferecedoras de produtos percebidos como idênticos não têm o que decidir sobre os preços e devem tomar os preços disponíveis no mercado. A terceira variável, com base no trabalho de Al-Hussari (2006), analisa de forma direta se há necessidade de colocação de preços exatamente iguais aos concorrentes. Al-Hussari (2006) argumenta que apenas podem ser consideradas formadoras de preços aquelas empresas com condições de influenciar os preços, isto é, aquelas empresas sem necessidade de seguir os preços determinados pelos demais participantes do mercado.

Assim, foram enquadradas como tomadoras de preços: (i) todas as empresas ofertantes de commodities, de acordo com a resposta à questão dos três principais produtos vendidos; (ii) todas as empresas atuantes no mercado de consumo que oferecem produtos não percebidos pelos clientes como diferenciados, de acordo com a resposta à questão 1b; e (iii) todas as demais empresas que afirmaram ter a necessidade de colocar preços iguais aos da concorrência, de acordo com a resposta à questão $1 \mathrm{~g}$. Como formadoras de preços foram enquadradas as empresas que (i) não ofertavam commodities; (ii) ofertavam produtos altamente diferenciados no mercado de consumo e, portanto, não precisavam fixar preços idênticos à concorrência; e (iii) afirmavam ter condições de colocar preços diferentes aos dos concorrentes.

O segundo construto, captado pela 11 questão do questionário, refere-se à diferenciação e foi apurado a partir da análise da customização, isto é, do grau de atendimento a solicitações específicas dos clientes nos atributos e funcionalidades dos produtos ofertados pela empresa. Ele diz respeito a atributos intrínsecos (e.g., estética, ética, espiritualidade e diversão) e/ou extrínsecos (e.g., eficiência, excelência, status e reputação) (Holbrook, 1996).

O uso de informações foi definido de forma similar aos trabalhos prévios, nos quais os profissionais são questionados sobre a intensidade com que usam informações de custos, de concorrentes, de valor e de quaisquer outros tipos (e.g., Ingenbleek, Debruyne, Frambach \& Verhallen, 2003; Avlonitis \& Indounas, 2006; Ingenbleek \& Van der Lans, 2013; Liozu \& Hinterhuber, 2013). Nesse sentido, a questão 2 foi aplicada para identificar as informações utilizadas pelos respondentes no processo de estabelecimento dos preços.

O terceiro construto tomou como base os estudos prévios. Captada pela $3^{\text {a }}$ questão, a fórmula de estabelecimento dos preços tende a ser apoiada em um tipo específico de informação, afinal, as empresas, por mais que se embasem em variadas perspectivas, acabam priorizando uma delas para simplificarem o processo decisório (Marn \& Rosiello, 1992; Smith \& Nagle, 1994; Ingenbleek et al., 2003).

Finalmente, a essência do estabelecimento dos preços é marcada pelos custos quando a margem é arbitrária e não conecta os custos a outros tipos de informações. Quando a margem é variável e adaptável para promover a conexão entre os custos e os preços de referência da concorrência nas tomadoras de preços ou do valor que o produto oferece ao cliente nas formadoras de preços, os custos não configuram a essência, por mais que a combinação "custos mais margem" seja usada. Para operacionalizar este último construto, foram usadas as questões $6 \mathrm{a}, 6 \mathrm{f}$ e $6 \mathrm{~g}$ em todas as empresas, assim como a $1 \mathrm{j}$ nas tomadoras e $7 \mathrm{f}$ nas formadoras.

$\mathrm{Na}$ amostra, 188 empresas se enquadram como tomadoras de preços e 192 empresas como formadoras de preços. A Tabela 1 detalha a composição da amostra e ainda sumariza a estatística descritiva dos constructos da pesquisa. Vale esclarecer que, exceto para o enquadramento e para as fórmulas empregadas, as questões solicitaram aos respondentes manifestar seu grau de concordância diante de uma escala Likert de 5 pontos, cujos extremos iam do 1 (discordância total) ao 5 (concordância total). Em todas as questões, que empregaram tal escala, ao menos um respondente assinalou tanto o ponto mínimo (1) quanto o ponto máximo (5). 
Tabela 1. Descritiva dos dados coletados para a amostra

\begin{tabular}{|c|c|c|c|c|}
\hline Constructo & Estatística descritiva & Tomadoras & Formadoras & Total \\
\hline \multirow{9}{*}{$\begin{array}{c}\text { Enquadramento: } \\
\text { tomadoras ou } \\
\text { formadoras de preços }\end{array}$} & Questões: Principais produtos; $1 \mathrm{~b} ; \mathbf{1 g}$ & Qtde. & Qtde. & Qtde. \\
\hline & Commodities & 40 & - & 40 \\
\hline & B2C - Produtos não diferenciados & 26 & - & 26 \\
\hline & $\mathrm{B} 2 \mathrm{C}$ - Produtos diferenciados - não influencia preços & 8 & - & 8 \\
\hline & B2C - Produtos diferenciados - pode influenciar preços & - & 16 & 16 \\
\hline & B2B - não influencia preços & 104 & - & 104 \\
\hline & B2B - pode influenciar preços & - & 172 & 172 \\
\hline & EC - não influencia preços & 10 & - & 10 \\
\hline & EC - pode influenciar preços & - & 4 & 4 \\
\hline \multirow{4}{*}{ Diferenciação } & Questão: 1l & & & \\
\hline & Média & 3,13 & 3,82 & 3,48 \\
\hline & Mediana & 3 & 4 & 4 \\
\hline & Desvio Padrão & 1,46 & 1,30 & 1,42 \\
\hline \multirow{4}{*}{$\begin{array}{l}\text { Uso de informações } \\
\text { de custos }\end{array}$} & Questões: 2a; 2b; 2c; 2d; 2e; 2f & & & \\
\hline & Média & 3,89 & 4,05 & 3,97 \\
\hline & Mediana & 4 & 4 & 4 \\
\hline & Desvio Padrão & 1,30 & 1,17 & 1,24 \\
\hline \multirow{4}{*}{$\begin{array}{l}\text { Uso de informações } \\
\text { da concorrência }\end{array}$} & Questões: 2k; 2l; 2m; 2n & & & \\
\hline & Média & 3,58 & 3,20 & 3,38 \\
\hline & Mediana & 4 & 3 & 3 \\
\hline & Desvio Padrão & 1,20 & 1,15 & 1,19 \\
\hline \multirow{4}{*}{$\begin{array}{l}\text { Uso de informações } \\
\text { de valor }\end{array}$} & Questões: $2 \mathrm{~g} ; 2 \mathrm{~h} ; 2 \mathrm{i} ; 2 \mathrm{j}$ & & & \\
\hline & Média & 3,38 & 3,78 & 3,58 \\
\hline & Mediana & 4 & 4 & 4 \\
\hline & Desvio Padrão & 1,28 & 1,12 & 1,22 \\
\hline \multirow{9}{*}{$\begin{array}{l}\text { Fórmulas de } \\
\text { estabelecimento dos } \\
\text { preços empregadas }\end{array}$} & Questão: 3 & & & \\
\hline & Custos mais margem (apenas) & 112 & 153 & 265 \\
\hline & Mais de uma fórmula (com custos mais margem) & 11 & 8 & 19 \\
\hline & Preços da concorrência & 36 & 9 & 45 \\
\hline & Valor & 4 & 19 & 23 \\
\hline & Mercado & 15 & - & 15 \\
\hline & Mais de uma fórmula (sem custos mais margem) & 5 & 2 & 7 \\
\hline & Tentativa e erro & 2 & - & 2 \\
\hline & Outra & 3 & 1 & 4 \\
\hline \multirow{4}{*}{$\begin{array}{c}\text { Essência - tomadoras: } \\
\text { ausência de preços de } \\
\text { referência }\end{array}$} & Questão: 1j & & & \\
\hline & Média & 2,55 & $\mathrm{~N} / \mathrm{A}$ & 2,55 \\
\hline & Mediana & 2 & $\mathrm{~N} / \mathrm{A}$ & 2 \\
\hline & Desvio Padrão & 1,46 & $\mathrm{~N} / \mathrm{A}$ & 1,46 \\
\hline \multirow{4}{*}{$\begin{array}{c}\text { Essência - } \\
\text { formadoras: "custos } \\
\text { mais margem" } \\
\text { impera valor }\end{array}$} & Questão: 7f & & & \\
\hline & Média & $\mathrm{N} / \mathrm{A}$ & 2,78 & 2,96 \\
\hline & Mediana & N/A & 3 & 3 \\
\hline & Desvio Padrão & N/A & 1,26 & 1,08 \\
\hline \multirow{4}{*}{$\begin{array}{l}\text { Essência custos: } \\
\text { margem definida pelo } \\
\text { depto. financeiro }\end{array}$} & Questão: 6a & & & \\
\hline & Média & 1,69 & 2,07 & 1,88 \\
\hline & Mediana & 1 & 2 & 1 \\
\hline & Desvio Padrão & 0,99 & 1,22 & 1,13 \\
\hline
\end{tabular}




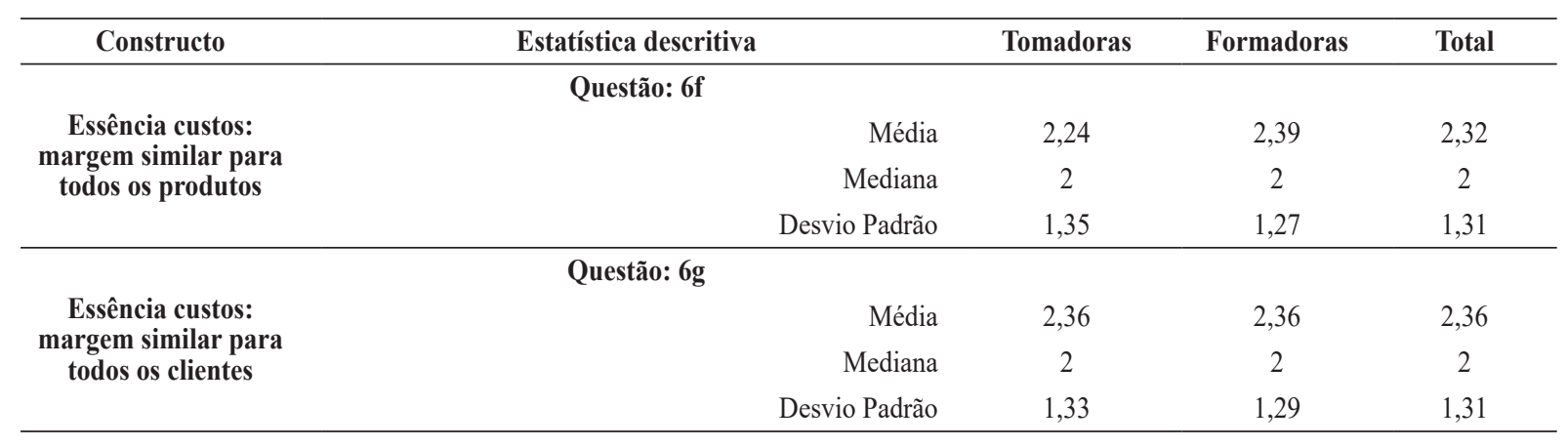

Fonte: Dados da pesquisa.

Nota: B2C - Mercado de consumo, B2B - Mercado industrial, EC - Engenharia e construção.

\section{ANÁLISE E DISCUSSÃO DOS RESULTADOS}

\subsection{Poder de formar preços e diferenciação de produtos}

Se a diferenciação do produto for associada ao poder de formar preços, deveria ser observada maior presença de formadoras de preços quando os produtos têm maior nível de diferenciação (Hipótese 1). $\mathrm{O}$ teste de média não paramétrico de Mann-Whitney entre as amostras de empresas formadoras e tomadoras de preços indica maior diferenciação de produtos para as formadoras de preços (sig. 0,000).

Para ilustrar o impacto da influência tomadoras versus formadoras de preços, o mapa perceptual na Figura 1 associa os dois tipos de empresas em relação à diferenciação do produto. Ele foi elaborado a partir da Análise de Correspondência, que examina relações de interdependência entre variáveis (Hair, Anderson, Tatham \& Black, 2009). Nesta pesquisa, está sendo analisada a relação entre a diferenciação e o poder (ou não) de definir os preços.

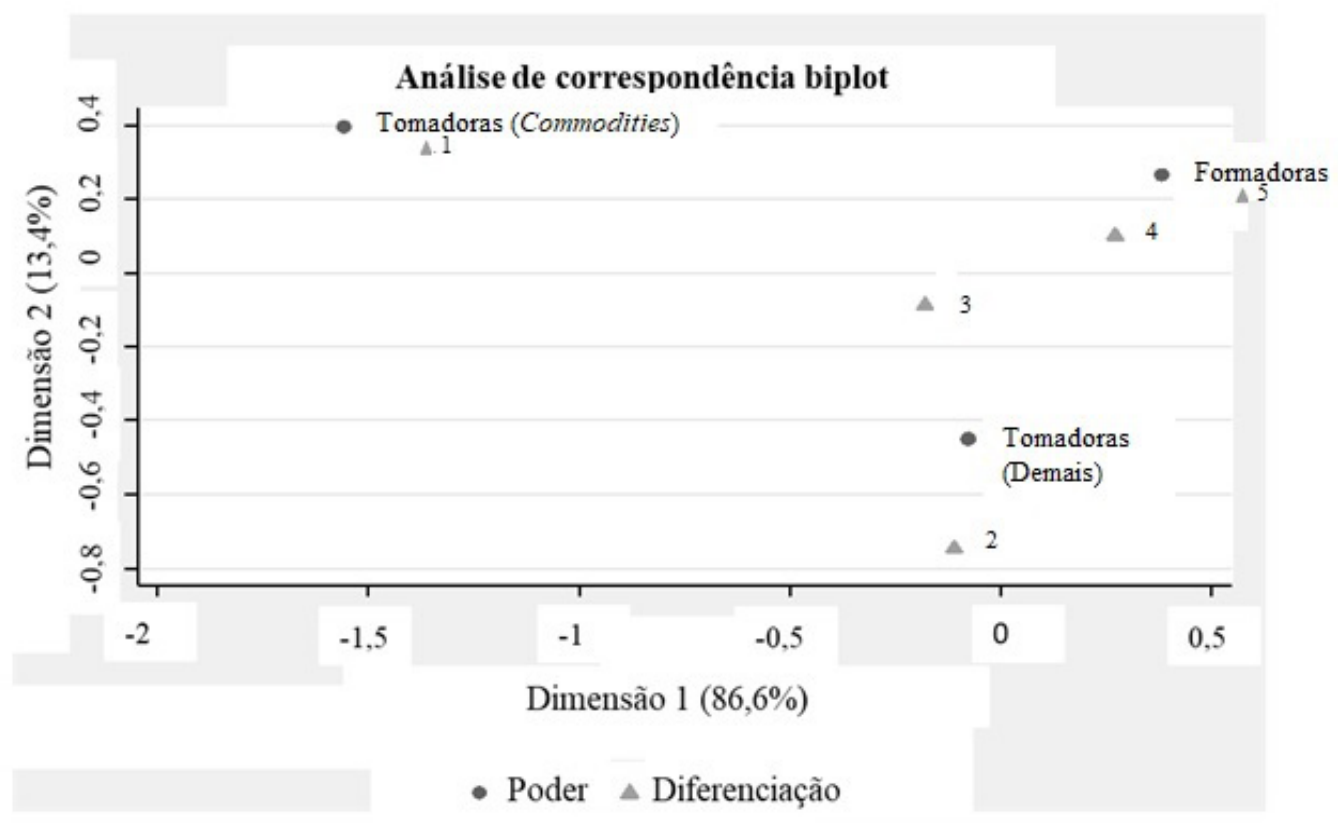

Figura 1. Mapa perceptual: diferenciação dos produtos e poder de formar preços Fonte: Dados da pesquisa. 
Observamos que as formadoras de preços estão associadas ao oferecimento de produtos customizados (pontos mais altos de diferenciação - 4 e 5), enquanto as tomadoras de preços estão associadas ao oferecimento de produtos padronizados (pontos 1 e 2). As empresas de commodities são as que estão associadas ao menor nível de diferenciação. Logo, confirmando Banterle, Carraresi e Cavaliere (2011), notamos que a diferenciação dos produtos está relacionada com o poder de formar preços, e consequentemente, empresas com produtos menos diferenciados possuem processos de fixação de preços menos associados à informação do valor dos produtos aos clientes e mais relacionados às ofertas dos concorrentes.

\subsection{Poder de formar preços e uso de informações}

Cada classe de empresa, definida de acordo com o poder de definir os preços, usaria preponderantemente um tipo de informação para fixar seus preços. As empresas tomadoras de preços usariam preços das ofertas concorrentes e dos custos para estabelecerem os preços (Hipótese 2a) e as formadoras de preços as informações dos custos (Hipótese 2b). Porém, ambas em alguma medida poderiam considerar o valor do produto ao cliente. A Tabela 2 mostra a intensidade de uso dos diferentes tipos de informação (custos, concorrência e valor) no estabelecimento dos preços pelo método da entropia informacional.

A entropia informacional trata da dispersão das respostas e revela onde é encontrada menor variação, seguindo o método de Zeleny (1982). Quanto maior for a entropia, menor o peso informacional e menor a dispersão dos resultados; quanto menor for a entropia, maior o peso informacional e maior a variabilidade nas respostas (Santos, Beuren \& Conte, 2017). Maiores graus de entropia representam menores efeitos surpresa, ou seja, menor variação nas respostas obtidas (Rocha, Hein, Lavarda \& Nascimento, 2011). Quanto menor a entropia, maior o efeito surpresa, pois nem todos os respondentes assinalam os mesmos pontos na escala proposta.

Tabela 2. Poder de formar preços e informações usadas

\begin{tabular}{|c|c|c|c|c|c|}
\hline \multicolumn{6}{|c|}{ Formadoras de preços } \\
\hline Informação & Tipo & $\begin{array}{c}\text { Entropia } \\
\text { parcial }\end{array}$ & Peso & Média & $\begin{array}{l}\text { Desvio } \\
\text { padrão }\end{array}$ \\
\hline Margem desejada & Custos & 0,9955 & 0,0274 & 4,4271 & 0,8950 \\
\hline Custos variáveis & Custos & 0,9953 & 0,0285 & 4,3177 & 0,9084 \\
\hline Impostos & Custos & 0,9951 & 0,0297 & 4,4219 & 0,9233 \\
\hline Custos fixos & Custos & 0,9927 & 0,0443 & 4,1354 & 1,0597 \\
\hline $\begin{array}{r}\text { Necessidades e } \\
\text { interesses dos clientes }\end{array}$ & Valor & 0,9921 & 0,0477 & 3,9323 & 1,0489 \\
\hline \multicolumn{6}{|c|}{ Tomadoras de preços (Commodities e Demais) } \\
\hline Informação & Tipo & $\begin{array}{c}\text { Entropia } \\
\text { parcial }\end{array}$ & Peso & Média & $\begin{array}{l}\text { Desvio } \\
\text { padrão }\end{array}$ \\
\hline Custos variáveis & Custos & 0,9922 & 0,0392 & 4,2447 & 1,1108 \\
\hline $\begin{array}{r}\text { Nível de preço dos } \\
\text { concorrentes }\end{array}$ & Concorrência & 0,9906 & 0,0468 & 3,8191 & 1,1183 \\
\hline Impostos & Custos & 0,9905 & 0,0475 & 4,1915 & 1,2041 \\
\hline Margem desejada & Custos & 0,9888 & 0,0558 & 3,9415 & 1,2461 \\
\hline $\begin{array}{l}\text { Preços de produtos } \\
\text { similares dos concorrentes }\end{array}$ & Concorrência & 0,9887 & 0,0566 & 3,5266 & 1,1536 \\
\hline
\end{tabular}

Fonte: Dados da pesquisa.

A intensidade de uso de informações de custos é alta em toda a amostra, especialmente nas formadoras de preços. As empresas formadoras de preços mesclam os custos com informações de valor (nenhuma informação da concorrência aparece em meio as cinco de uso mais intenso). Já nas tomadoras de preços os custos são mesclados a informações das ofertas da concorrência.

A Tabela 3 confirma a diferença estatística significativa, obtida no teste Mann-Whitney, entre as duas categorias de empresas para o uso da informação de valor e de concorrência. O uso de informações de custos não apresentou diferença, pois é intenso em ambas as categorias. 
Tabela 3. Comparação entre formadoras e tomadoras na intensidade de uso de informações

\begin{tabular}{|c|c|c|}
\hline Hipótese Nula & Sig. & Decisão \\
\hline $\begin{array}{r}\text { A distribuição do uso de informações de custos é a mesma entre as categorias de } \\
\text { enquadramento }\end{array}$ & 0,236 & Não rejeitar a hipótese nula \\
\hline $\begin{array}{r}\text { A distribuição do uso de informações de valor é a mesma entre as categorias de } \\
\text { enquadramento }\end{array}$ & 0,000 & Rejeitar a hipótese nula \\
\hline $\begin{array}{r}\text { A distribuição do uso de informações de concorrência é a mesma entre as categorias de } \\
\text { enquadramento }\end{array}$ & 0,000 & Rejeitar a hipótese nula \\
\hline
\end{tabular}

Fonte: Dados da pesquisa.

Por fim, a média de uso de informações de custos, apresentada na Tabela 1, é elevada tanto em formadoras $(4,05)$ quanto em tomadoras de preços $(3,89)$. Esse resultado confirma que nas tomadoras, ainda que os preços reflitam o mercado, as informações de custos de produção podem ser usadas para viabilizar a prática dos preços, como indicado em Strickland (2007). Quanto ao uso dos preços das ofertas da concorrência, o uso é mais intenso nas tomadoras $(3,58)$ do que nas formadoras $(3,20)$. E as informações sobre o valor dos produtos ao cliente são mais empregadas nas formadoras $(3,78)$ do que nas tomadoras de preços $(3,38)$. Estes resultados mostram que as informações de valor são enfatizadas pelas formadoras de preços.

\subsection{Poder de formar preços e fórmulas empregadas}

A partir da Tabela 2, podemos observar que nos dois tipos de empresas a informação de margem é intensamente utilizada. O que mostra que as fórmulas do tipo "custos mais margem" poderiam ser encontradas tanto nas tomadoras quanto nas formadoras de preços (Hipótese 3).

As respostas dos profissionais indicam que a principal fórmula usada para fixação dos preços é “custos mais margem", tanto nas tomadoras quanto nas formadoras. Na amostra, 265 respondentes afirmaram que é dessa forma que operacionalizam o processo de fixação de preços. Além disso, 19 respondentes assumiram articular formas para definir os preços, sendo que uma dessas formas é "custos mais margem". A Figura 2 ilustra as principais formas de estabelecimento dos preços.

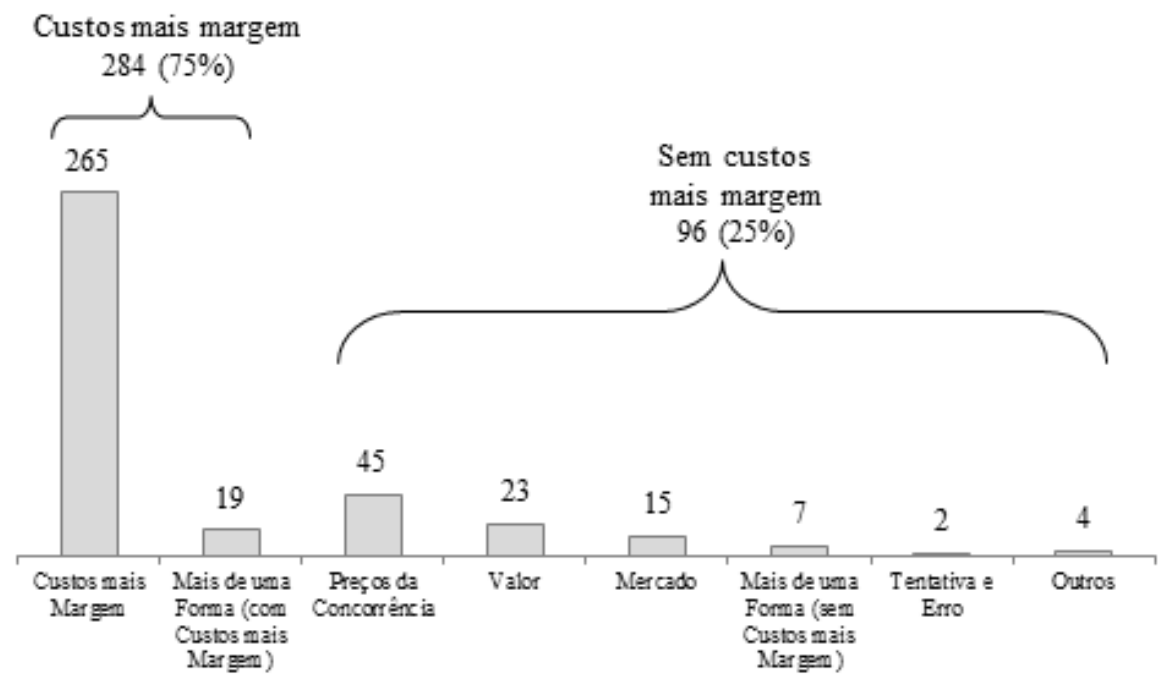

Figura 2. Formas de estabelecer os preços

Fonte: Dados da pesquisa. 
As fórmulas do tipo "custos mais margem” estão mais presentes nas formadoras de preços, mas também estão presentes nas tomadoras, consonante com os achados de Drury e Tayles (2006). São 123 tomadoras de preços (112 apenas "custos mais margem" + 11 "custos mais margem" articulado a outra fórmula) e 161 formadoras de preços (153 apenas "custos mais margem" + 8 articulado com outras fórmulas). O uso dessa fórmula não significa, contudo, que os preços são embasados unicamente nos custos, ele simplesmente demonstra que os preços são definidos a partir de uma base de custos.

\subsection{Poder de formar preços e essência do estabelecimento dos preços}

Por fim, o uso da fórmula "custos mais margem” não seria necessariamente sinônimo de um estabelecimento dos preços que tem os custos como essência (Hipótese 4). Afinal, nas tomadoras de preços, o uso dessa fórmula não eliminaria a necessidade de seguir preços de referência. Conforme demonstra a Tabela 4, 55\% do total de tomadoras de preços relatam tal necessidade, que é ainda mais acentuada nas empresas de commodities $(75 \%)$.

Tabela 4. Empresas tomadoras de preços e necessidade de seguir preços de referência

\begin{tabular}{rcccccc}
\hline \multicolumn{5}{c}{ No nosso segmento, não há preços de referência que precisam ser estritamente seguidos } \\
\hline \multicolumn{3}{c}{ Tomadoras (Commodities) } & \multicolumn{2}{c}{ Tomadoras (Demais) } & \multicolumn{2}{c}{ Total de Tomadoras } \\
Manifestação & Qtde. & $\mathbf{\%}$ & Qtde. & $\mathbf{\%}$ & Qtde. & \% \\
\hline Discordância & $\mathbf{3 0}$ & $\mathbf{7 5}$ & $\mathbf{7 3}$ & $\mathbf{4 9}$ & $\mathbf{1 0 3}$ & $\mathbf{5 5}$ \\
Neutralidade & 2 & 5 & 32 & 22 & 34 & 18 \\
Concordância & 8 & 20 & 43 & 29 & 51 & 27 \\
Total & $\mathbf{4 0}$ & $\mathbf{1 0 0}$ & $\mathbf{1 4 8}$ & $\mathbf{1 0 0}$ & $\mathbf{1 8 8}$ & $\mathbf{1 0 0}$ \\
\hline
\end{tabular}

Fonte: Dados da pesquisa.

Constatamos que a maior parte das tomadoras de preços segue rigorosamente os preços de referência, conforme preconizado por Hofstrand (2007), independentemente da mecânica utilizada para operacionalizar o processo. Ainda, há diferenças estatísticas significativas entre as 123 empresas que aderem e as 65 empresas que não aderem à combinação "custos mais margem" para operacionalizar os preços de referência (teste de MannWhitney). Curiosamente, aquelas empresas que usam "custos mais margem” são as que mais precisam seguir preços de referência (média de 2,740 contra média de 2,200 para empresas que não usam "custos mais margem”). Ou seja, a utilização de fórmulas pautadas nos custos não impede as tomadoras de preços de se adequarem ao preço do mercado.

Neste contexto, pode surgir a dúvida: de que forma as tomadoras de preços operacionalizam a fixação dos preços baseados na fórmula "custos mais margem" e, ainda assim, estabelecem preços coerentes com os preços de referência? Nossa argumentação é de que o elemento chave capaz de conectar as informações de custos com preços das ofertas da concorrência é a "margem esperada". Ao avaliar como a margem é deliberada na empresa, pode-se analisar se: (a) os preços são definidos considerando apenas o quanto é preciso para cobrir os custos e obter lucro, ou (b) se os preços são definidos a partir dos custos, contudo levando em consideração também os preços das ofertas concorrentes.

A Tabela 5 mostra que as tomadoras de preços da amostra, em geral, discordam ou não contestam a afirmação de que os segmentos de clientes ou produtos têm margem similares, portanto, a margem é um aspecto que varia com o produto ou segmento. Também discordam que a margem é definida de forma isolada pelo departamento financeiro. 
Tabela 5. Tomadoras de preços e a margem esperada das fórmulas "custos mais margem"

\begin{tabular}{|c|c|c|c|c|c|c|}
\hline \multicolumn{7}{|c|}{ 1-A margem colocada sobre os custos é definida isoladamente pelo departamento financeiro } \\
\hline \multirow{2}{*}{ Manifestação } & \multicolumn{2}{|c|}{ Tomadoras (Commodities) } & \multicolumn{2}{|c|}{ Tomadoras (Demais) } & \multicolumn{2}{|c|}{ Total de Tomadoras } \\
\hline & Qtde. & $\%$ & Qtde. & $\%$ & Qtde. & $\%$ \\
\hline Discordância & 8 & 80 & 89 & 79 & 97 & 79 \\
\hline Neutralidade & 1 & 10 & 14 & 12 & 15 & 12 \\
\hline Concordância & 1 & 10 & 10 & 9 & 11 & 9 \\
\hline Total & 10 & 100 & 113 & 100 & 123 & 100 \\
\hline \multicolumn{7}{|c|}{2 - Todos os nossos produtos têm margens parecidas } \\
\hline \multirow{2}{*}{ Manifestação } & \multicolumn{2}{|c|}{ Tomadoras (Commodities) } & \multicolumn{2}{|c|}{ Tomadoras (Demais) } & \multicolumn{2}{|c|}{ Total de Tomadoras } \\
\hline & Qtde. & $\%$ & Qtde. & $\%$ & Qtde. & $\%$ \\
\hline Discordância & 6 & 60 & 63 & 56 & 69 & 56 \\
\hline Neutralidade & 2 & 20 & 26 & 23 & 28 & 23 \\
\hline Concordância & 2 & 20 & 24 & 21 & 26 & 21 \\
\hline Total & 10 & 100 & 113 & 100 & 123 & 100 \\
\hline \multicolumn{7}{|c|}{3 - Todos os nossos segmentos de clientes têm margens parecidas } \\
\hline \multirow{2}{*}{ Manifestação } & \multicolumn{2}{|c|}{ Tomadoras (Commodities) } & \multicolumn{2}{|c|}{ Tomadoras (Demais) } & \multicolumn{2}{|c|}{ Total de Tomadoras } \\
\hline & Qtde. & $\%$ & Qtde. & $\%$ & Qtde. & $\%$ \\
\hline Discordância & 5 & 50 & 65 & 58 & 70 & 57 \\
\hline Neutralidade & 3 & 30 & 22 & 19 & 25 & 20 \\
\hline Concordância & 2 & 20 & 26 & 23 & 28 & 23 \\
\hline Total & 10 & 100 & 113 & 100 & 123 & 100 \\
\hline
\end{tabular}

Fonte: Dados da pesquisa.

Já as formadoras de preços, por mais que tenham poder para fixar os preços em decorrência da diferenciação de seus produtos, têm certa limitação para forçar os clientes a comprarem seus produtos a qualquer preço. Logo, o preço final deveria espelhar o valor oferecido ao cliente, independente da forma adotada (Hofstrand, 2007).

Não constatamos diferença estatística significativa na percepção da possibilidade de definir os preços, sem ter que avaliar o valor oferecido aos clientes, entre os grupos que usam e não usam fórmulas do tipo "custos mais margem". Ademais, das 161 formadoras de preços que fixam os preços a partir de fórmulas do tipo "custos mais margem", 64 (40\%) discordam da afirmação de que não precisam avaliar o valor entregue aos clientes simplesmente porque utilizam fórmulas do tipo "custos mais margem” (Tabela 6).

Tabela 6. Empresas formadoras de preços e desconsideração do valor do bem

\begin{tabular}{ccc}
\hline \multicolumn{3}{c}{ A utilização dos custos e da margem possibilita formar o preço sem ter que avaliar } \\
o valor oferecido aos clientes
\end{tabular}

Fonte: Dados da pesquisa.

Assim, pode-se questionar para as formadoras de preços: como os preços operacionalizados por fórmulas do tipo “custos mais margem" estão associados ao valor oferecido ao cliente? Novamente, nosso argumento é de que a "margem esperada" conecta o valor entregue ao cliente e os custos da empresa, pois os preços poderiam ser fixados considerando (a) apenas o montante necessário para cobrir os custos e obter lucro, ou (b) partindo dos custos, mas incorporando o valor oferecido ao cliente. 
A Tabela 7 mostra que as formadoras de preços discordam da afirmação de que a margem é deliberada de forma isolada pelo departamento financeiro. Tal fato estaria alinhado à noção de que a fixação de preços integraria os departamentos de marketing e vendas versus controladoria e finanças, por tradicionalmente assumirem diferentes perspectivas na questão de viabilidade de produtos (Carricano, Trinquecoste \& Mondejar, 2010). Ainda, a maior parte das formadoras discorda que todos os produtos e todos os clientes têm margens semelhantes, o que pode indicar uma margem planejada para cada produto e para cada cliente e, portanto, pode atuar como um elemento conector dos custos ao valor.

Tabela 7. Empresas formadoras de preços e a margem esperada das fórmulas "custos mais margem"

\begin{tabular}{|c|c|c|}
\hline \multicolumn{3}{|c|}{$\begin{array}{c}1 \text { - A margem colocada sobre os custos é definida isoladamente pelo } \\
\text { departamento financeiro }\end{array}$} \\
\hline Manifestação & Qtde. & $\%$ \\
\hline Discordância & 108 & 67 \\
\hline Neutralidade & 25 & 16 \\
\hline Concordância & 28 & 17 \\
\hline Total & 161 & 100 \\
\hline \multicolumn{3}{|c|}{2 - Todos os nossos produtos têm margens parecidas } \\
\hline Manifestação & Qtde. & $\%$ \\
\hline Discordância & 86 & 53 \\
\hline Neutralidade & 38 & 24 \\
\hline Concordância & 37 & 23 \\
\hline Total & 161 & 100 \\
\hline \multicolumn{3}{|c|}{3 - Todos os nossos segmentos de clientes têm margens parecidas } \\
\hline Manifestação & Qtde. & $\%$ \\
\hline Discordância & 91 & $\mathbf{5 7}$ \\
\hline Neutralidade & 31 & 19 \\
\hline Concordância & 39 & 24 \\
\hline Total & 161 & 100 \\
\hline
\end{tabular}

Fonte: Dados da pesquisa.

Assim, tanto formadoras quanto tomadoras de preços utilizam fórmulas do tipo "custos mais margem" sem que os custos sejam, necessariamente, a única informação considerada para a fixação de preços. Deixando, assim, espaço para supor que informações sobre "valor entregue ao cliente" também sejam consideradas no processo de fixação de preços no caso das formadoras de preços. Para as tomadoras de preços, a margem pode conectar os custos e os preços das ofertas concorrentes, já que há a necessidade de observar os preços de referência.

\section{DISCUSSÃO E CONCLUSÃO}

De forma análoga a estudos prévios, constatamos que fórmulas do tipo "custos mais margem" e informações das ofertas da concorrência são utilizadas de forma ampla pelas empresas da amostra. Contudo, diferentemente das pesquisas anteriores, buscamos demonstrar que tal uso não indica, necessariamente, que a essência da fixação dos preços é direcionada pelos custos e pela concorrência. Primeiro, porque depende se a empresa é formadora ou tomadora de preços, e segundo porque outras informações são levadas em consideração pelas empresas para o estabelecimento dos preços.

É costume na literatura de custos e preços que se desenvolveu concluir que os preços são baseados nos custos simplesmente porque a combinação "custos mais margem" é empregada. Conforme argumentamos no estudo, não há razões para fazer esta associação direta no processo de fixação de preços. É possível que, por intermédio da margem, preços definidos a partir dos custos reflitam ou se aproximem do valor do produto ou serviço ou correspondam aos preços dos concorrentes. 
Para estudos similares de fixação de preços, sugerimos que empresas tomadoras e formadoras de preços sejam analisadas de forma segregada, pela natural base de formação do preço. Ademais, ressaltamos que o processo de fixação do preço em si, o uso de fórmulas e como elas embutem pressupostos e estratégias de preços podem ser mais explorados no mercado nacional. Por exemplo, como os impostos e diferentes custos são considerados nas fórmulas “custos mais margem", e se sempre o resultado da fórmula é seguido. Ou, se a empresa, para preservação de market share ou nível de competição, abre mão de parte da margem para posicionar seus preços abaixo das ofertas concorrentes. Estudos futuros podem também aprofundar as discussões sobre as razões que levam essas empresas a adotar a essência dos custos no seu processo de estabelecimento de preços, e ainda como o grau de diferenciação ao logo do tempo permanece ou é alterado.

Por fim, empresas podem adotar diferentes posturas dependendo da linha de produtos, algumas sendo mais tomadoras de preços outras mais formadoras, podendo coexistir diferentes posturas de fixação de preço dentro da mesma empresa ou unidade estratégica de negócios. Um aspecto a ser observado é como estas unidades coexistem e se relacionam com os departamentos financeiros e controladoria de uma mesma organização. E se eventuais práticas de fixação de preços, rotinas ou fórmulas presentes em sistemas eletrônicos (ERP) podem se aplicar mais a uma unidade ou à outra, ou beneficiar mais uma ou outra.

\section{REFERÊNCIAS}

Al-Hussari, H. (2006). The influence of contextual factors on cost system design and pricing decisions: a study of UK companies in the food processing and other industries (Doctoral thesis, Huddersfield University Business School, Huddersfield, England).

Armstrong, J. S., \& Overton, T. S. (1977). Estimating nonresponse bias in mail surveys. Journal of Marketing Research, 14(3), 396-402.

Avlonitis, G. J., \& Indounas, K. A. (2005). Pricing objectives and pricing methods in the service sector. Journal of Services Marketing, 19(1), 47-57. DOI: https://doi.org/10.1108/08876040510579398

Avlonitis, G. J., \& Indounas, K.A. (2006). How are prices set? An exploratory investigation in the Greek services sector. Journal of Product \& Brand Management, 15(3), 203-213. DOI: https://doi.org/10.1108/10610420610668649

Banterle, A., Carraresi, L., \& Cavaliere, A. (2011). What is the role of marketing capability to be a price maker? An empirical analysis in Italian food SMEs. Economia \& Diritto Agroalimentare, XVI(2), 245-261.

Calabrese, A., \& Francesco, F. (2014). A pricing approach for service companies: service blueprint as a tool of demand-based pricing. Business Process Management Journal, 20(6), 906-921. DOI: https://doi.org/10.1108/ BPMJ-07-2013-0087

Carricano, M., Trinquecoste, J. F. \& Mondejar, J.A. (2010). The rise of the pricing function: origins and perspectives. Journal of Product \& Brand Management, 19(7), 468-476. DOI: https://doi.org/10.1108/10610421011086883

Chand, U. (2009). Pricing strategies in the Canadian frozen chicken sector (Master's thesis, Department of Rural Economy, University of Alberta, Edmonton, Canada).

D'Aveni, R. A. (2009). Beating the commodity: how to maximize your competitive position and increase your pricing power. Boston, MA: Harvard Business Press.

Drury, C., \& Tayles, M. (2006). Profitability analysis in UK organizations: an exploratory study. The British Accounting Journal, 38(4), 405-425. DOI: https://doi.org/10.1016/j.bar.2006.05.003

Dutta, S., Zbaracki, M. J., \& Bergen, M. (2003). Pricing process as a capability: a resource-based perspective. Strategic Management Journal, 24(7), 615-630. DOI: https://doi.org/10.1002/smj.323

Edwards, R. (1952). The pricing of manufactured products. Economica, 19(75), 298-307. DOI: https://doi. org/10.2307/2550658

Foxall, G. R. (1972). A descriptive theory of pricing for marketing. European Journal of Marketing, 6(3), 190-194. DOI: https://doi.org/10.1108/EUM0000000005139

Foxall, G. R. (1980). The logic of price decision-making. Management Decision, 18(5), 235- 245. DOI: https:// doi.org/10.1108/eb001243

Hair, J. F., Anderson, R. E., Tatham, R. L., \& Black, W. C. (2009). Análise multivariada de dados. (6a ed.). Porto Alegre: Bookman. 
Harper, D. (1966). Price policy and procedure. New York: Harcourt, Brace \& World.

Haynes, J. B., \& Wilkens, P. L. (1974). The pricing of marketing research services. Business Horizons, 17(5), 7580. DOI: https://doi.org/10.1016/0007-6813(74)90043-3

Hinterhuber, A. (2008). Customer value-based pricing strategies: why companies resist. Journal of Business Strategy, 29(4), 41-50. DOI: https://doi.org/10.1108/02756660810887079

Hinterhuber, A. (2016). The six pricing myths that kill profits. Business Horizons, 59(1), 71-83. DOI: https://doi. org/10.1016/j.bushor.2015.09.002

Hofstrand, D. (2007). Commodities versus differentiated products. Disponível no site da Iowa State University: https://www.extension.iastate.edu/agdm/wholefarm/html/c5-203.html

Holbrook, M. B. (1996). Customer value - a framework for analysis and research. Advances in Consumer Research, 23, 138-142.

Indounas, K. A. (2006). Making effective pricing decisions. Business Horizons, 49(5), 415-424. DOI: https://doi. org/10.1016/j.bushor.2006.02.003

Ingenbleek, P. T. M. (2007). Value-informed pricing in its organizational context: literature review, conceptual framework, and directions for future research. Journal of Product \& Brand Management, 16(7), 441-458. DOI: https://doi.org/10.1108/10610420710834904

Ingenbleek, P. T. M., Debruyne, M., Frambach, R. T., \& Verhallen, T. M. M. (2003). Successful new product pricing practices: a contingency approach. Marketing Letters, 14(4), 289-305. DOI: https://doi.org/10.1023/ B:MARK.0000012473.92160.3d

Ingenbleek, P. T. M., \& van der Lans, I. A. (2013). Relating price strategies and price-setting practices. European Journal of Marketing, 47(1/2), 27-48. DOI: https://doi.org/10.1108/03090561311285448

Lere, J. C. (1979). What cost is right for pricing? The CPA Journal, 49(7), 76-77.

Liozu, S. M., \& Hinterhuber, A. (2013). Pricing orientation, pricing capabilities, and firm performance. Management Decision, 51(3), 594-614. DOI: https://doi.org/10.1108/00251741311309670

Marn, M. V., \& Rosiello, R. L. (1992). Managing price, gaining profit. Harvard Business Review, 70(5), 84-94.

Maroco, J., \& Garcia-Marques, T. (2006). Qual a fiabilidade do alfa de Cronbach? Questões antigas e soluções modernas. Laboratório de Psicologia, 4(1), 65-90. Disponível no site do Instituto Universitário de Ciências Psicológicas, Sociais e da Vida: http://hdl.handle.net/10400.12/133

Maxwell, S. (1998). Pricing education in the United States of America: responding to the needs of business. Journal of Product \& Brand Management, 7(4), 336-341. DOI: https://doi.org/10.1108/10610429810229861

Oxenfeldt, A. R. (1961). Pricing for marketing executives. San Francisco: Wadsworth Publishing Company.

Piercy, N. F., Cravens, D. W., \& Lane, N. (2010). Thinking strategically about pricing decisions. Journal of Business Strategy, 31(5), 38-48. DOI: https://doi.org/10.1108/02756661011076309

Rocha, I., Hein, N., Lavarda, C. E. F., \& Nascimento, S. (2011). A presença da entropia da informação no controle orçamentário em ambiente inovador. Revista de Administração e Inovação, 8(2), 81-105. DOI: https://doi. org/10.5773/rai.v8i2.566

Santos, V., Beuren, I. M., \& Conte, A. (2017). Uso de instrumentos do sistema de controle gerencial em empresas incubadas. Revista Contabilidade Vista \& Revista, 28(3), 103-132.

Simons, F. (2012). Price-takers have three choices. FT.com. Disponível na base de dados ProQuest ABI/INFORM Complete

Smith, G. E., \& Nagle, T. T. (1994). Financial analysis for profit-driven pricing. Sloan Management Review, 35(3), 71-84.

Strickland, L. (2007). Price taker or price maker - cost matters. CarolinaNewswire.com. Disponível em http:// carolinanewswire.com/news/News.cgi?database=columns.db\&command=viewone \&id=297

Tishlias, D. P. (1984). The influence of alternative cost allocations on the new product pricing decision: an empirical investigation (Doctoral dissertation, Department of Accounting of the College of Business Administration, University of Cincinnati, Cincinnati $[\mathrm{OH}]$ ). 
Wentz, T.E. (1966). Realism in pricing analyses. Journal of Marketing, 30(2), 19-26. DOI: https://doi. org/10.2307/1249059

Zeleny, M. (1982). Multiple criteria decision making. New York, NY: McGraw-Hill.

\section{Como citar este artigo}

Amaral, J.V., \& Guerreiro, R. (2018). Reflexões sobre o estabelecimento de preços a partir dos custos e dos preços das ofertas concorrentes: a lacuna pode não ser tão profunda. Revista de Contabilidade e Organizações, 12:e141359. DOI: http://dx.doi.org/10.11606/issn.1982-6486.rco.2018.141359

\section{APÊNDICE A}

\section{Questionário de pesquisa sobre o estabelecimento dos preços em indústrias no Brasil}

\section{Instruções}

Este questionário foi elaborado para identificar características do estabelecimento dos preços em empresas industriais instaladas no Brasil.

As questões aplicam-se ao estabelecimento dos preços dos produtos do principal segmento da sua empresa, ou seja, daquele segmento que tem a maior expressividade nos seus negócios.

As respostas ao questionário devem espelhar a situação que predomina na sua empresa.

\section{CARACTERIZAÇÃO GERAL DO PRINCIPAL SEGMENTO}

1- Em que extensão você concorda com as seguintes assertivas:

\begin{tabular}{|c|c|}
\hline $\mathrm{a}$ & Muitas outras empresas atuam no nosso segmento (temos muitos concorrentes) \\
\hline $\mathrm{b}$ & Os clientes consideram que nossos produtos são diferentes dos produtos oferecidos pelos nossos concorrentes \\
\hline $\mathrm{c}$ & $\begin{array}{l}\text { Os atributos e funcionalidades dos nossos produtos são diferentes dos atributos e funcionalidades dos produtos dos } \\
\text { nossos concorrentes }\end{array}$ \\
\hline $\mathrm{d}$ & O nível de qualidade dos nossos produtos é elevado em relação aos nossos concorrentes \\
\hline e & Nossos concorrentes conseguem copiar os nossos produtos com facilidade \\
\hline $\mathrm{f}$ & O nível de preço dos nossos produtos é elevado (preço premium) \\
\hline $\mathrm{g}$ & $\begin{array}{l}\text { Como nossos produtos são diferenciados, não precisamos colocar preços exatamente iguais aos preços dos nossos } \\
\text { concorrentes }\end{array}$ \\
\hline h & $\begin{array}{l}\text { Temos dificuldade em identificar os preços cobrados pelos nossos concorrentes (é escassa a divulgação prévia dos } \\
\text { preços em sites, catálogos, etc.) }\end{array}$ \\
\hline $\mathrm{i}$ & $\begin{array}{l}\text { A dificuldade de obtenção dos preços dos concorrentes explica nossa necessidade de usar informações alternativas no } \\
\text { estabelecimento dos preços }\end{array}$ \\
\hline $\mathrm{j}$ & No nosso segmento, não há preços de referência que precisam ser estritamente seguidos \\
\hline $\mathrm{k}$ & Temos muitos clientes \\
\hline 1 & $\begin{array}{l}\text { Priorizamos a produção customizada, ou seja, frequentemente atendemos a solicitações específicas dos clientes na } \\
\text { elaboração dos nossos produtos }\end{array}$ \\
\hline
\end{tabular}




\section{INFORMAÇÕES E FÓRMULAS USADAS NO ESTABELECIMENTO DOS PREÇOS}

Nesta parte do questionário, o objetivo é levantar detalhes sobre as informações e fórmulas usadas no processo de estabelecimento dos preços dos produtos do principal segmento.

2- Indique a intensidade do uso das seguintes informações no estabelecimento dos preços:

\begin{tabular}{c|cll}
\hline \multirow{4}{*}{$\begin{array}{c}\text { Informações de } \\
\text { custos }\end{array}$} & $\mathrm{a}$ & Custos variáveis/diretos dos produtos \\
\cline { 2 - 3 } & $\mathrm{b}$ & Custos fixos de fabricação dos produtos \\
\cline { 2 - 3 } & $\mathrm{c}$ & Impostos sobre vendas \\
\cline { 2 - 3 } & $\mathrm{d}$ & Despesas (administrativas, comerciais e financeiras) \\
\cline { 2 - 3 } $\begin{array}{c}\text { Informações do } \\
\text { valor oferecido }\end{array}$ & $\mathrm{e}$ & Valores dos investimentos (em maquinários, instalações, etc.) \\
\cline { 2 - 3 } & $\mathrm{f}$ & Margem desejada para os produtos (margem de contribuição, de lucro bruto ou de lucro líquido) \\
\cline { 2 - 3 } & $\mathrm{h}$ & Necessidades e interesses dos clientes \\
\hline \multirow{4}{*}{$\begin{array}{c}\text { Informações da } \\
\text { concorrência }\end{array}$} & $\mathrm{i}$ & Percepções dos clientes em relação aos produtos \\
\cline { 2 - 3 } & $\mathrm{j}$ & Comparação entre os benefícios oferecidos e os custos trazidos aos clientes pelos produtos \\
\cline { 2 - 3 } & $\mathrm{k}$ & Preços de produtos concorrentes que são iguais aos nossos produtos \\
\cline { 2 - 3 } & $\mathrm{m}$ & Nível de preço dos concorrentes \\
\cline { 2 - 3 } & $\mathrm{n}$ & Estratégia de preço dos concorrentes \\
\hline Outras inform. & $\mathrm{o}$ & Por exemplo, informações econômicas, políticas, tecnológicas, regulatórias, ecológicas, sociais \\
\hline
\end{tabular}

Likert, 5 pontos: 1 - Baixa intensidade de uso, e 5 - Alta intensidade de uso

3- Indique dentre as seguintes afirmações qual demonstra a PRINCIPAL forma de operacionalização do estabelecimento dos preços

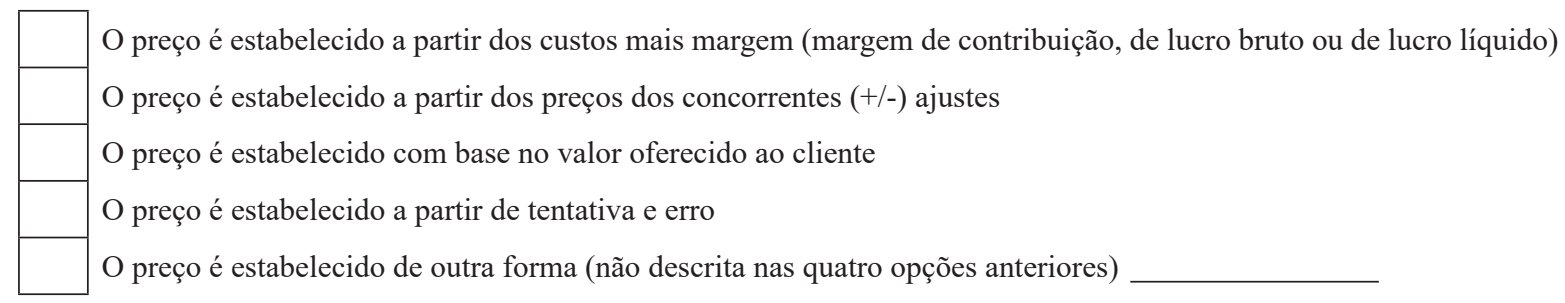

4- Alguma fórmula matemática de custos mais margem é usada no estabelecimento dos preços?

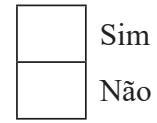

\section{CUSTOS MAIS MARGEM}

Nesta parte do questionário, o objetivo é levantar detalhes do uso dos custos e da margem no processo de estabelecimento dos preços.

\section{Custos}

5- Em que extensão você concorda com as seguintes assertivas:

\begin{tabular}{ll}
\hline a & Todos os custos fixos de produção (por exemplo, aluguel da fábrica, salário do supervisor, etc.) devem \\
NECESSARIAMENTE ser incluídos nas fórmulas de preços
\end{tabular}

Likert, 5 pontos: 1 - Discordo Totalmente, e 5 - Concordo Totalmente 


\section{Margem}

6- Em que extensão você concorda com as seguintes assertivas:

\begin{tabular}{cl}
\hline a & A margem colocada sobre os custos é definida isoladamente pelo departamento financeiro \\
\hline b & A lucratividade desejada é a principal informação considerada para definição da margem \\
\hline c & $\begin{array}{l}\text { A definição da margem independe da consideração de características específicas dos produtos (por exemplo, a } \\
\text { margem de produtos simples é similar à margem de produtos sofisticados) }\end{array}$ \\
\hline d & A definição da margem independe da consideração de características específicas dos clientes, como porte e localidade \\
\hline e & A definição da margem independe da consideração da importância que os clientes vêem nos produtos \\
\hline f & Todos os nossos produtos têm margens parecidas \\
\hline g & Todos os nossos segmentos de clientes têm margens parecidas \\
\hline h & $\begin{array}{l}\text { Priorizamos o uso de margens percentuais, ou seja, usamos MAIS margens na forma percentual (\% somada aos } \\
\text { custos) do que na forma unitária (valor em R } \$ \text { somado aos custos) }\end{array}$ \\
\hline
\end{tabular}

Likert, 5 pontos: 1 - Discordo Totalmente, e 5 - Concordo Totalmente

\section{Custos mais margem}

Obs.: Considere que o "valor oferecido aos clientes" corresponde à combinação entre os benefícios e os custos dos produtos, segundo a PERCEPÇÃO DOS CLIENTES

7- Em que extensão você concorda com as seguintes assertivas:

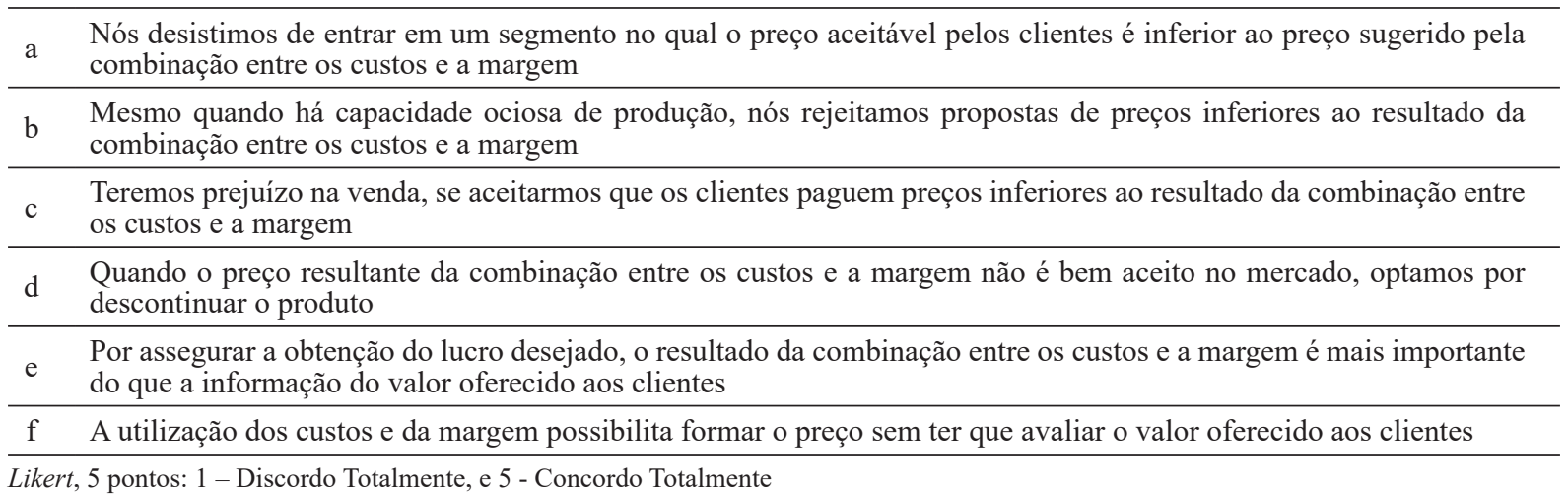

\section{FATORES RELACIONADOS AO ESTABELECIMENTO DOS PREÇOS}

Nesta parte do questionário, o objetivo é identificar os fatores que influenciaram sua empresa a decidir como os preços dos produtos do principal segmento seriam estabelecidos.

8- Em que extensão você concorda com as seguintes assertivas:

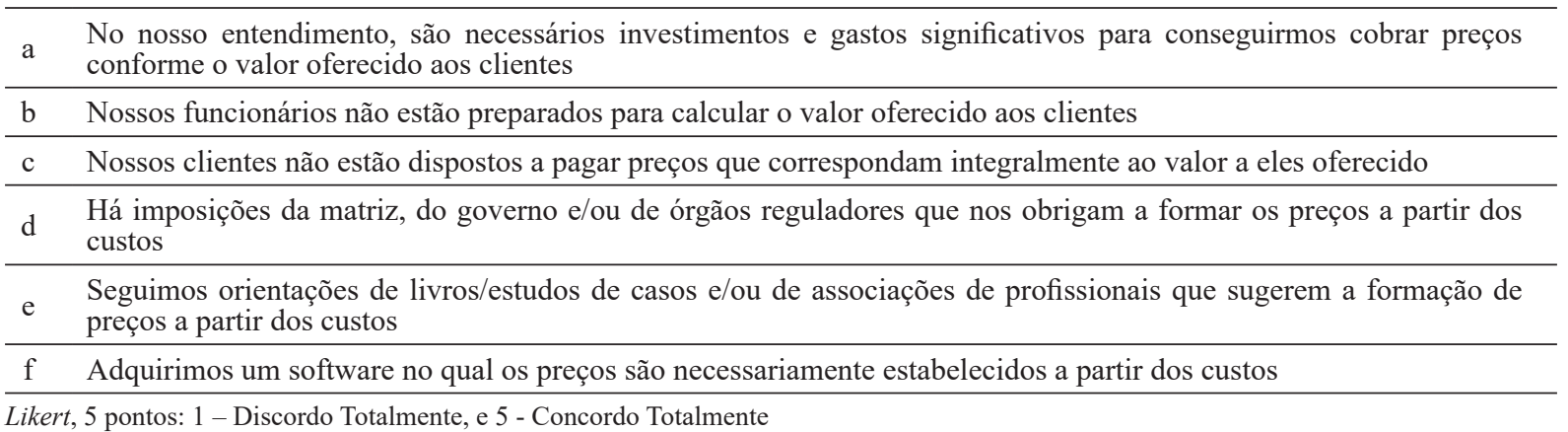




\section{CONCLUSÃO}

Esta é a última seção do questionário. Nela, são trazidas perguntas para conhecer um pouco mais sobre os respondentes e sobre as empresas que compõem a amostra da pesquisa.

Nome do respondente:

Empresa:

E-mail:

Departamento/área que atua na empresa (Preços, Marketing, Vendas, Financeiro ou Outro - qual?):

Cargo que atua na empresa (Analista, Supervisor/Coordenador, Gerente/Diretor ou Outro - qual?):

Há APROXIMADAMENTE quanto tempo você, ou o principal responsável pelo processo atua no estabelecimento dos preços? (Anos)

Existe na empresa área especificamente dedicada a estabelecer preços? (Sim; Não)

Existindo área especificamente voltada ao estabelecimento dos preços, há APROXIMADAMENTE quanto tempo ela existe? (Anos)

APROXIMADAMENTE, quantos empregados trabalham na empresa? (Até 19 empregados, De 20 a 99 empregados, De 100 a 499 empregados, Mais de 500 empregados)

No principal segmento, a sua empresa é a líder de mercado, ou seja, é a empresa com maior participação de vendas? (Sim; Não)

Quais são os três principais produtos vendidos pela empresa? 